\title{
STRUCTURAL MODEL OF BURNOUT DETERMINING FACTORS WITH ATHLETES
}

\author{
Mihail Georgiev, Nadya Mladenova,, Liliya Doncheva
}

\begin{abstract}
Introduction: In the context of structural equation modeling we analyzed the influence of stress and recovery factors, emotional intelligence, and a burnout on the athlete's satisfaction. The model is recursive and contains 11 observed variables and two not observed. The analysis reveals the degree of influence of the variables included in the model on the athlete's satisfaction, the direct and indirect impact of the variables, and their role as mediators in the survey model. Methodology: The research was done among 60 athletes practicing individual and team sports. We used: Athlete Burnout Questionnaire; Athlete Satisfaction Questionnaire; Recovery Stress Questionnaire for Athletes (RESTQ-sport); Emotional Intelligence Test.

Results: The results of the analysis show that stress and recovery, emotional and physical exhaustion and a decline in personal achievement have the greatest impact on satisfaction. These variables also play the role of mediators between emotional intelligence and athlete's satisfaction.

Conclusions: The study provides considerable insight into the problem of the influence of stress and recovery, emotional intelligence and burnout on athletes' satisfaction. It substantiates and adds to previous studies in the field and provides practical solutions which could be implemented in the sports-educational process.
\end{abstract}

Key words: emotional intelligence, stress, recovery, satisfaction

\section{Introduction}

In the recent years burnout has become a major issue in sports theory and practice. The research has been aimed at revealing the factors which determine it - physical and psychic stress loads, social stress, interpersonal relations in the sports team, personal characteristics. The peculiarities in the burnout structure and the consequences of its manifestations have been revealed (Dale \& Weinberg, 1990; Vealey et al., 1998; Price \& Weiss, 2000; Readeke et al., 2002).

It has been established that burnout could be seen among athletes with different sports experience, including children and adolescents (L. Straus, 2014). The idea of burnout in the field of children and adolescents' sport has been presented very exactly and exhaustively by the American Medical Society for Sports Medicine (DiFiori, J., H. Benjamin, J. Brenner, A. Gregory, N. Jayanthi, G. Landry, A. Luke, 2014).

The number of research on burnout in sport has become more numerous. But the results bring up lots of questions for discussion instead of adding to and building on a more complete image of its nature. The main reason for that is the lack of scientific theoretical models which can be used as a base for particular empirical studies.
On the base of critical analysis and summary of the achievements of the foreign authors in the field, M. Georgiev, I. Tosheva and D. Fenerova (2010) made an attempt to reveal the manifestations of burnout in sport and its peculiarities. Regarding burnout in sport the authors outlined a few major practical guidelines.

The manifestations of burnout in sport are specific. That is why the term should be made more operational. One of the most peculiar characteristics of sport is the exceptionally high physical and physic loads among athletes and coaches, which is not characteristic of the other spheres of social activities.

On the base of comparative theoretical analysis, the authors accept that the definition given by Raedeke (1997) outlines most exactly the characteristics of the researched phenomenon. According to this definition burnout is a syndrome which could be observed after physical and emotional exhaustion, sports devaluation, and a decrease in achievements. This definition comprises the understanding of the manifestations of burnout in other professional fields as well, but it reflects the sport specific high physical and psychic loads, tiredness and fatigue.

The research of burnout in sport requires an inclusion of additional parameters connected with 
the public character of sports activities and its social significance. On the other hand, a number of psychic phenomena should be included in the research. Those are phenomena which are related to stress and coping with it - typological peculiarities, emotional intelligence, self-control and self-regulation, individual style of emotional reaction, stress coping strategies, stable motivation trends, etc. (M. Georgiev, I. Tosheva, D. Fenerova, 2010).

One of the consequences of chronic tension and stress among athletes is the occurance of the negative psychic state - burnout. At the same time, sports activities are a source of significant and unique positive emotions and feelings for athletes. One of the manifestations of these affects is athletes' satisfaction with sport. This, in turn, influences the expectated and achieved results, as well as dedication to sport (Chelladurai, 1984).

In the last two decades authors have researched the issues related both to burnout and to athletes' satisfaction, but one could hardly find many works which analyze their interaction. Altahayneh (2014) finds out there is a high negative correlation among all burnout components and the aspects of satisfaction.

A wide range of factors affect athletes' satisfaction. Chelladurai and Riemer (1997) offer a theoretical model comprising the main aspects and components of satisfaction, which are connected with the factors determining them: Individual performance (satisfaction with one's own work, improvement, achieved personal goals); Team performance (satisfaction with the overall team work, with the achieved goals, with the aspiration to constant perfection); Development of abilities (satisfaction with coach's work as regards the development of athletes' abilities and talent); Strategy (satisfaction with coach's strategy and tactics); Coach's personal attitude towards athletes (satisfaction with the social support and positive feedback); Trainings and instructions (satisfaction with coach's teaching, training and instructions); Collective responsibility (satisfaction with each member of the team's contribution to achieving the aims and tasks of the team); Social responsibility (satisfaction with the team's support and contribution to the development of each of its members); Ethics (satisfaction with the relationships in the team); Integrity of the team (satisfaction with the group integration, coordination and interactions for achievement of the aims of the team); Loyalty (athletes' satisfaction with their own loyalty and contribution to the team's success); Budget (satisfaction with the financial conditions for the development of the team); Medical staff (satisfaction with the team's medical staff); Academic support (athletes' satisfaction with the academic services and support); External agents (satisfaction with the support on behalf of external for the team and club organizations).

The emergence of stress and burnout is caused by a number of personal characteristics: typological peculiarities, personal traits, psychic endurance, emotional reaction and activity style. The peculiarities of emotional intelligence also have a significant influence. The role of emotional intelligence in sport has been relatively slightly researched.

Emotional intelligence in sport has been a subject of intense studies in the last few years. But they are rather insufficient for revealing its specific characteristic manifestations, its role in sports career and in high performance sport. The surveys have been made in many directions; there is no unification among them, which impedes their systematization and the development of a common concept about emotional intelligence in sport.

In an exhaustive theoretical study, including 36 scientific surveys related to emotional intelligence in sport and motor activities, Laborde, Dosseville and Allen (2016) find out that it could be viewed as a personal trait. In the context of sport, it is related to emotions, to the physiological response to psychic pressure, and to the more effective training and competitive activities. On the base of the analyzed surveys the authors offer a three-rank model where emotional intelligence is viewed on three levels: knowledge, abilities, and personal traits. The components of these three levels are in constant interaction, and the model can be used to predict this interaction.

Emotional intelligence affects self-regulation and athlete's way of thinking (B. Vaibhav, 2014). When high activation is needed, athletes with high emotional intelligence achieve it more easily. It is determined as a key factor for success in individual and mostly in team sports.

\section{Hypothesis of the research}

The intense training loads and the insufficient recovery time lead to the syndrome of overtrain- 
ing. The high levels of its manifestation determine burnout among athletes. Burnout is also influenced by emotional intelligence and athletes' satisfaction.

\section{Methodology}

The research was done among 58 athletes -26 men and 32 women. Twenty-eight of them practice individual kinds of sports and thirty - team sports. They are aged between 15 and 26 years and have sports experience of 1 to 15 years.

- Athlete Burnout Questionnaire (Raedake \& Smith, 2001). The test includes 23 items and a 5 -point Likert type scale for assessment of their degree of manifestation. There are three subscales: emotional and physical exhaustion; devaluation of the interest towards sport, and a decrease in personal achievements. The test has been adapted for Bulgarian conditions by Tosheva, Georgiev, Fenerova (2011).

- Athlete Satisfaction Questionnaire (Riemer \& Chelladurai, 1998). ASQ a multi-dimension questionnaire which includes 14 items and a 5-point Likert type scale. It assesses 4 components which determine satisfaction: trainings and instructions; team performance; individual performance; coach's personal attitude to athletes. We have used the Bulgarian version of the test in our research (M. Georgiev, D. Fenerova, I. Tosheva, 2011).

- Emotional Intelligence Test (Wood, Tolley, 2007). The test includes six items and three options to reply. It assesses the coefficient of overall emotional intelligence.

- Recovery Stress Questionnaire for Athletes (RESTQ-sport). The test includes 74 items and 19 subscales. A 4-point Liker type scale is used for assessment of their degree of manifestation. Four general scales are outlined, on the base of the nineteen subscales, as general factors: general stress; general recovery; stress in sport; recovery in sport (Davis, Orzeck, Keelan, 2006).

\section{Results}

The analysis of the empirical data was made with the method of structural equation modeling (SEM), with IBM AMOS Graphics 22.

The co-variation matrixes were analyzed with the criterion Mahalanobis Distance. When $d f=12$ (the number of the observed independent variables included in the model), the critical level $\chi^{2}=19.67$. There were higher values with two of the researched individuals. They were excluded from the database in the further analys.

Several structural models were analyzed.

In the first model the variables, related to stress and recovery, are presented in two factors - Stress (general stress; sport-specific stress) and Recovery (general recovery; sport-specific recovery). This model cannot be identified. The problems arise exactly out of these two factors. The exploratory factor analysis shows that they are integrated into one common factor.

In the second structural model the observed variables, related to stress and recovery, are united in one factor - Stress (Fig. 1).

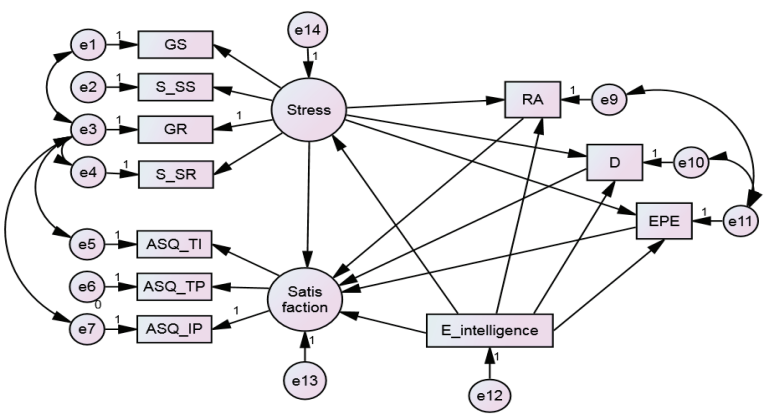

Fig. 1. Modified structural model of Burnout Determining Factors with Athletes

Legend:

GS - general stress

IP - individual performance PT - personal treatment of the coach

RA - reduced sense of accomplishment

GR - general recovery

S_SR - sport specific recovery

TI - training and instructions

$\mathrm{D}$ - devaluation of interest in sport

EPE - emotional and physical

exhaustion

E_intelligence - common

$\mathrm{TP}$ - team performance

emotional intelligence

The factor loading analysis shows that the variable ASQ_PT (personal treatment of the coach) is of very low value $-\lambda=0,03$, and therefore it was excluded from the model. In order to improve the model we used the data from Modification Indices. Six correlation links were included between the measurement error associated with an observed variable.

Notes for Model

The model is recursive.

Sample size $=56$ 
Chi-square $=32.733$

Degrees of freedom $=31$

Probability level $=.382$

The criterion Chi-square is greatly influenced by the size of the researched sample. It can determine some discrepancies between the observed and predicted co-variations and it can be assumed that the model does not correspond to the empirical data and there are statistically significant differences between the observed and predicted meanings. In order to avoid the rejection of the analyzed model we used the following alternative indexes (differentiated into three groups): Absolute Fit Measures; Relative Fit Measures; Parsimonious Fit Measures (table 2).

Table 2

Fit Measures

\begin{tabular}{|l|c|l|l|l|c|c|c|c|}
\hline \multicolumn{3}{|c|}{ Absolute } & \multicolumn{3}{c|}{ Relative } & \multicolumn{3}{c|}{ Parsimonious } \\
\hline Test & Threshold & Value & Test & Threshold & Value & Test & Threshold & Value \\
\hline$\chi^{2}$ & $\mathrm{p}>.05$ & .382 & CFI & $>.95$ & .993 & PNFI & $>.5$ & .502 \\
\hline GFI & $>.90$ & .913 & NFI & $>.90$ & .891 & PCFI & $>.5$ & .560 \\
\hline RMSR & $<.05$ & .025 & IFI & $>.90$ & .994 & & & \\
\hline RMSEA & $<.10$ & .032 & RFI & $>.90$ & .806 & & & \\
\hline
\end{tabular}

The indexes for evaluation of the model allow us to presume it as completely adequate of the really existing interrelations and interdependences between the researched phenomena.

A great number of direct and indirect directions of influence were presented in the analyzed structural model. In order to assess the power of indirect impacts, the degree to which a certain variable plays the role of a mediator of the influence of one factor on another, we brought out the criterion $\mathrm{z}$ (Standard Deviation) with critical significance level of 1.96. If $\mathrm{z}>1.96$ - the factor is a mediator between the other two factors (Zero, 2015).

The variables from the burnout structure do not play the role of mediators between emotional intelligence and satisfaction. The factor stress does not play this role either. The components of burnout structure have only a direct influence on satisfaction. The most influential one is RA ( $\beta=-.56)$; (EFE $=\beta-.39 ; \mathrm{D}=\beta-.1)$. The direct influence of stress on satisfaction is little $(\beta=-.23)$. Its indirect influence through burnout components is more significant (Stress $>>R A-\beta=-.32$; Stress $>>D-\beta$ $=-.67$; Stress $>>\mathrm{EPE}-\beta=-.57)$.

The high levels of general and sport specific stress and the low levels of general and sport specific recovery lead to an increase in burnout levels in the three components. High levels of burnout lead to a decrease in athletes' satisfaction.

The emotional intelligence does not affect signifi- cantly satisfaction and burnout components. It affects more significantly the factor Stress $-\beta=-.39$.

In order to make a more profound analysis of the model we used feedback loops (Satisfaction >> Stress; Satisfaction >> RA; Satisfaction >> D; Satisfaction $\gg$ EPE. In this non-recursive model, the five co-variance matrixes are not positively definite. This solution is not admissible.

\section{Conclusions}

The study provides considerable insight into the problem of the influence of stress and recovery, emotional intelligence and burnout on athletes' satisfaction. It substantiates and adds to previous studies in the field and provides practical solutions which could be implemented in the sports-educational process.

\section{References}

Altahayneh, Z. (2014). Effects of Coaches' Behaviors on Athletes' Satisfaction and Burnout. Scholars' Press.

Chelladurai, P. (1984). Discrepancy between preferences and perceptions of leadership behavior and satisfaction of athletes in varying sports. Journal of Sport Psychology, Volume: 6 Issue: 1, pp. 27-41

Chelladurai, P., Riemer, H. (1997). A Classification of Facets of Athlete Satisfaction. Journal of Sport Management. 11, pp. 133-159

Dale, J., \& Weinberg, R. (1990). Burnout in sport: A review and critique Journal of Applied Sport Psychology, 2, pp. 67-83.

Davis, H., Orzeck, T. and Keelan, P. (2007). Psychometric item evaluations of the Recovery-Stress Questionnaire for athletes. Psychology of Sport and Exercise, Vol.8 No.6 pp.917-938 
DiFiori, J., H. Benjamin, J. Brenner, A. Gregory, N. Jayanthi, G. Landry, A. Luke. Overuse Injuries and Burnout in Youth Sports: A Position Statement from the American Medical Society for Sports Medicine. Clin J Sport Med, 2014; 24(1), pp. 3-20.

Freudenberger, H., Richelson, G. (1980). Burn-out: The high cost of high achievement. New York: Anchor Pres, Doubleday \& Company, Inc.

Georgiev, M., I. Tosheva, D. Fenerova. (2010). Бърнаут - специфична проява на стрес в спорта. Пети международен конгрес „Спорт, стрес, адаптация”. [Burnout - a specific manifestation of stress in sports]. Fifth International Congress "Sports, stress, adaptation". -: Sport and Science, Extraordinary Number., 2010, Part II, pp. 420-424.

Georgiev, M., I. Tosheva, D. Fenerova. (2011). Адаптация на теста за оценка на удовлетвореността на спортиста - ASQ (Riemer and Chelladurai, 1998). [Adaptation of the test to assess the athlete's satisfaction - ASQ (Riemer and Chelladurai, 1998)].- In: Personality. Motivation. Sports. Volume 16, NSA PRESS, Sofia, pp. 121-125

Laborde, S., Dosseville, F. and M. Allen. (2016). Emotional intelligence in sport and exercise: A systematic review. Scand J Med Sci Sports. 26(8), pp. 862-74

Price, M., \& Weiss, M. (2000). Relationships among coach burnout, coach behaviors, and athletes psychological response. The Sport Psychologist, 14, pp. 391-409.

Raedeke, T. (1997). Is athlete burnout more than just stress? A sport commitment perspective. Journal of Sport and Exercise Psychology, 19, pp. 396-417.

Raedeke, T., Lunney, K., \& Venables, K. (2002). Understanding athlete burnout: Coach perspectives. Journal of Sport Behavior, 25, pp. 181-206.

Raedeke, T., Smith, A. (2001). Development and preliminary validation of an athlete burnout measure. Journal of Sport and Exercise Psychology, 23, pp. 281-306.

Riemer, H., Chelladurai, P. (1998). Development of the Athlete Satisfaction Questionnaire. Journal of Sport and Exercise Psychology, 20:2, pp. 127-156

Straus, L. (2014). Burnout In Youth Athletes: Risk Factors, Symptoms, Diagnosis, and Treatment.http://www. momsteam.com/burnout-in-youth-athletes-risk-factors-symptoms-diagnosis-treatment. Created $03 / 21 / 2014$

Tosheva, I., M. Georgiev, M., D. Fenerova. (2011). Адаптация на теста за изследване на бърнаут при спортисти (ABQ - Raedeke and Smith, 2001). [Adaptation of the Athlete's Burnout Test (ABQ - Raedeke and Smith, 2001). VI National Congress on Psychology - 2011. Collection of scientific papers. Bulgarian Journal of Psychology, vol. 3-4, pp. 233-236.

Vaibhav, B. (2014). Emotional Intelligence: The Invisible Phenomenon in Sports. European Journal of Sports and Exercise Science, 3 (3), pp. 19-31

Vealey, R., Armstrong, L, Comar, W., \& Greenleaf, C. (1998). Influence of perceived coaching behaviors on burnout and competitive anxiety in female college athletes. Journal of Applied Sport Psychology, 10, pp. 297318.

Wood, R., X. Toly. (2007). Професионални тестове за емоционална интелигентност. [Professional Emotional Intelligence Tests]. "LOCUS”, Sofia.

Zero, M. (2015). Structural Equation Modeling in AMOS - SEM ZODA guided homework. https://www. youtube.com/watch?v=VUzxquMgADc.

Prof. Mihail Georgiev, PhD

National Sports Academy "Vassil Levski”, Sofia, Bulgaria, 1700

Department of Psychology, pedagogy end sociology e-mail: miger@abv.bg 